\title{
Behavioural dynamics of a clinical trial of sunscreens for reducing solar keratoses in Victoria, Australia
}

Jill Cockburn, Sandra C Thompson, Robin Marks, Damien Jolley, Penelope Schofield, David Hill
Centre for Behavioural Research in Cancer, Anti-Cancer Council of Victoria,

1 Rathdowne Street,

Carlton South,

Victoria, 3053,

Australia

J Cockburn

P Schofield

D Hill

Epidemiology and Social Research Unit, MacFarlane Burnet Centre for Medical

Research, PO Box 254, Fairfield, Victoria, 3078, Australia

S C Thompson

University of Melbourne, St Vincent's Hospital, 41 Victoria Parade, Fitzroy, Victoria, 3065, Australia

R Marks

Cancer Epidemiology Centre, Anti-Cancer Council of Victoria, 1 Rathdowne Street, Carlton South, Victoria, 3053, Australia

D Jolley

Correspondence to: Dr J Cockburn, Discipline of Behavioural Science in Relation to Medicine, University of Newcastle, Locked Bag 10, Wallsend, NSW 2287, Australia.

Accepted for publication 31 January 1997

\begin{abstract}
Objective-To determine whether the behaviour of participants based on perception of treatment group in a randomised trial contributed to clinical outcome.

Design-A double blind randomised controlled trial of the effect of daily application of SPF 17 broad spectrum sunscreen cream (or placebo) on solar keratoses. Setting-A rural city in Victoria, Australia. Residents aged 40 years or over were invited by letter to attend for a skin cancer screening check. Of these, 588 people with between one and 30 solar keratoses enrolled in the trial and 431 completed the trial, which extended over a six month period that included summer. Participants' perceptions of their treatment allocation, adherence with the treatment regimen, adoption of other sun protection behaviours, side effects, and perceptions of change in condition were measured at two monthly intervals.
\end{abstract}

Results-There were no significant differences between those who completed the study and those that did not for sex, age, treatment group, skin type, number of solar keratoses or correct perception of treatment group. Thirty per cent of those completing the study correctly guessed their treatment allocation, and people were just as likely to be right as to be wrong when they stated their opinion about their treatment allocation $(z=1.04$; $p=0.15)$. Study group, skin type, amount of time spent outdoors, presence of side effects, perceptions of change in skin condition did not significantly predict correct perception of treatment allocation. Multivariate analysis of variance indicated that adoption of other sun protection and adherence with cream use were not significantly affected by actual treatment allocation, correct perception of treatment allocation nor by their interaction. Poisson regression analysis showed a significantly lower difference ratio of solar keratoses in the sunscreen group compared with the placebo base cream group (OR $0.55 ; \mathrm{CI}=0.46,0.64)$, and for women compared with men $(O R=0.76 ; C I=0.63$, 0.93) but no independent effect of any of the indices of other sun protection or adherence.
Conclusions-A sufficient level of commitment to study procedures was achieved, so that trial participants did not adopt other behaviours that affected treatment outcomes. It is recommended that the potential threat to validity posed by the behaviour of participants be recognised at an early stage in planning of clinical trials, so that strategies to deal with this can be integrated into study protocols.

$(\mathcal{F}$ Epidemiol Community Health 1997;51:716-721)

Leventhal et al have postulated that the behavioural dynamics of a clinical trial can play an important part in determining clinical outcomes, particularly in trials with long time lines or those that entail a high degree of commitment from participants. Leventhal suggests that behaviours of participants that do not accord with study protocols are a source of variation that can affect response to randomisation and adherence to various components of trial protocols. If these behavioural factors interact differentially with treatment conditions, they can affect outcomes by adding to, subtracting from, or multiplying the effects in the experimental or control conditions.

Wherever feasible, randomised trials should be conducted double blind to avoid both bias in measurement, through participants perceiving effects that are not present, and bias in participation through differential adherence and drop out between treatment groups. ${ }^{2}$ If participants discern their allocated experimental condition, perhaps through noticing side effects or improvements that are attributed to treatment, both these biases may come into play. Moreover, if participants correctly perceive that they are in the placebo arm of a trial, they may adopt other compensatory behaviours to achieve the outcome they would expect from the experimental condition. Knowledge of treatment group may also result in differential adherence with treatment between experimental conditions. This would be a problem when the effectiveness of a treatment was dose dependent.

We have studied the effect of some of these factors in a double blind randomised controlled efficacy trial of regular use of sun protection factor (SPF) 17 broad spectrum sunscreen use on solar keratoses. ${ }^{3}$ (SPF 17 sunscreen results in a $94 \%$ reduction of radiation in the UVB wavelengths 290-320 $\mathrm{nm}$ ). The trial was undertaken in an Australian rural town over 


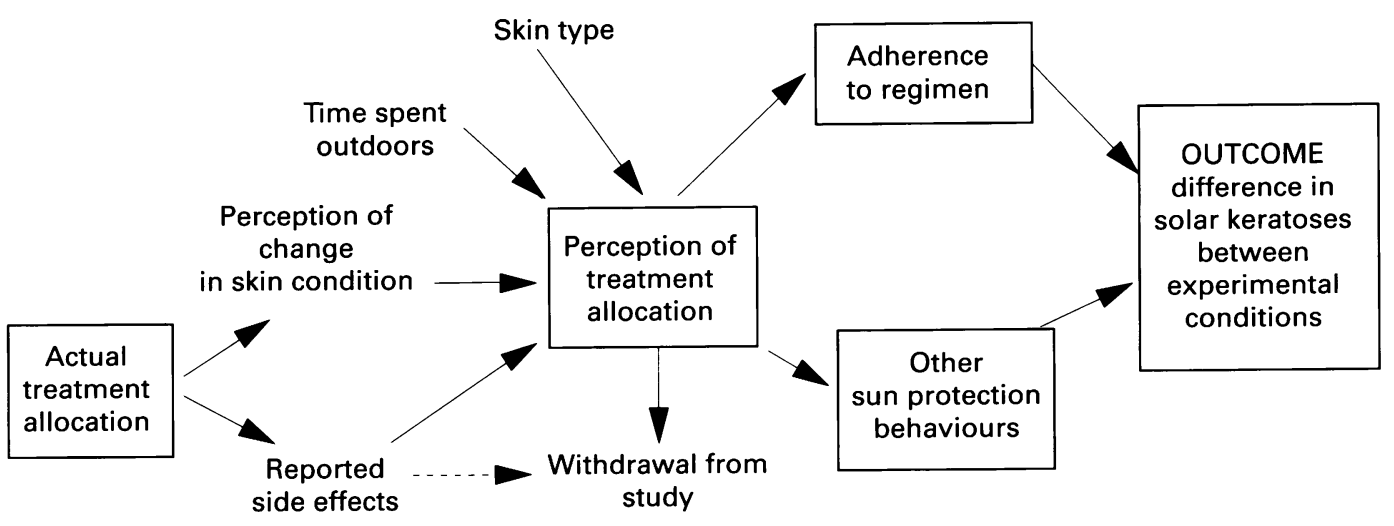

Figure 1 Proposed model for how extraneous factors may have affected outcomes in the trial.

summer, and participants applied either a sunscreen cream or the base cream minus the sunscreen actives to their head, neck, forearms, and hands. At the conclusion of the trial, fewer new solar keratoses developed and more remissions occurred in the sunscreen group than in the base cream group. The study concluded that regular use of sunscreens can prevent development of solar keratoses and by implication, reduce the risk of skin cancer in the long term. In this paper, we examine whether the behaviour of participants in the trial may have contributed to the observed outcome. Figure 1 shows a model outlining the factors that we examined and the hypothesised effects. We were particularly interested in the extent to which participants were able to guess the treatment condition to which they had been allocated and the determinants of this, and the effect of this perception on other behaviours that may have affected the major outcome of the trial (that is, reduction of solar keratoses).

\section{Methods}

The study methods have been described in detail elsewhere. ${ }^{3}$ Briefly, in September 1991, people aged 40 years and over in a rural district of Victoria, Australia were invited by letter to attend for free skin cancer screening by one of seven medical practitioners. The study was promoted on local television and in local newspapers, and the local council, rotary group, hospital and community health centre endorsed and supported the study.

Persons with between one and 30 solar keratoses were invited to participate in the study and after informed consent the participants were randomly allocated (double blind) to either a sunscreen or base cream group. The blinding procedure was explained to participants by the clinical examiner who initially described the study to potential participants, in the written material that was given to participants, and by the investigator who gained informed consent. Both creams were presented, quite truthfully, as alternative treatments with the base cream being described as a moisturiser (the base cream being equivalent to aqueous cream BPC (British Pharmacopoeia), a treatment often recommended to soften solar keratoses). Participants were instructed to apply around $1.5 \mathrm{ml}$ of cream to their head and neck, and to each forearm and hand each morning, and reapply if necessary during the day. The time of application of the cream was to be recorded in a daily diary. Participants were warned not to rely upon the cream for sun protection and to use other sun protection as they thought appropriate. They were told that the investigators preferred that participants did not use any other sunscreen on the areas where treatment cream was being applied. Follow up examinations occurred on three occasions over the next seven months until March 1992, covering the period of maximum daily sunlight in southern Australia. One week before each scheduled follow up appointment, participants were mailed a questionnaire and a seven day sun protection journal to complete and to bring to their appointment, along with daily diaries and bottles of cream. Table 1 gives the measurements obtained.

The major outcome variable was a ratio of the total number of solar keratoses at the end of the study to the number at the beginning, expressed as proportion of baseline lesions. ${ }^{3}$

\section{STATISTICAL ANALYSIS}

Logistic regression was used to determine whether actual treatment allocation, skin type, time spent outdoors in the study period, perceived change in skin condition, and the presence of side effects were significant predictors of correct perception of treatment allocation. A two way multivariate analysis of variance (MANOVA) was used to determine whether correct perception of treatment allocation, actual treatment allocation, and the interaction between the two, affected adherence with cream use and the scores on the indices of use of other sunscreens, use of other moisturisers, and covering up when outdoors. The effect of other sun protection behaviours (as measured by the indices) and adherence, independent of treatment and sex effects, on the difference ratio for solar keratoses was examined by multiplicative Poisson models, where the outcome was the ratio of the total number of solar keratoses at the end of the study to the number at the beginning, expressed as proportion of baseline lesions. 
Table 1 Measurement of variables

\begin{tabular}{|c|c|c|}
\hline Variable & Method and timing of data collection & Measurement \\
\hline $\begin{array}{l}\text { Demographic characteristics } \\
\text { and skin type }\end{array}$ & $\begin{array}{l}\text { Questionnaire completed at initial } \\
\text { examination }\end{array}$ & Sex, age, skin type (always burn, burn first then tan, always tan) \\
\hline $\begin{array}{l}\text { Perceptions of treatment } \\
\text { allocation }\end{array}$ & $\begin{array}{l}\text { From the questionnaires completed } \\
\text { before each of the } 3 \text { follow up clinical } \\
\text { examinations }\end{array}$ & $\begin{array}{l}\text { Question: "Which cream do you think you have been given?". } \\
\text { Possible responses: Definitely the sunscreen; probably the sunscreen; don't know; probably the } \\
\text { moisturiser; definitely the moisturiser. } \\
\text { Derived variable: Perceptions rated as either "definite" or "probable" that coincided with } \\
\text { actual treatment allocation on at least the last two questionnaire administrations were } \\
\text { classified as "correct". }\end{array}$ \\
\hline $\begin{array}{l}\text { Perceived change in skin } \\
\text { condition }\end{array}$ & $\begin{array}{l}\text { From the questionnaires completed } \\
\text { before each of the } 3 \text { follow up clinical } \\
\text { examinations }\end{array}$ & $\begin{array}{l}\text { Question: "Since we saw you at City Hall, do you think there has been any change in the skin } \\
\text { of your hands? (arms/face)" } \\
\text { Possible responses: Yes/No for each body part. } \\
\text { Derived variable: A score of } 1 \text { was given for each affirmative answer, and these were added } \\
\text { over time periods. }\end{array}$ \\
\hline Side effects & $\begin{array}{l}\text { Asked by the medical practitioner at } \\
\text { each of the } 3 \text { follow up clinical } \\
\text { examinations }\end{array}$ & $\begin{array}{l}\text { Question: "Have skin reactions prevented you from applying the cream on any occasion?" } \\
\text { Possible responses: Yes/No } \\
\text { Derived variable: The person was considered to have side effects if this had happened at least } \\
\text { once. }\end{array}$ \\
\hline $\begin{array}{l}\text { Adherence to treatment } \\
\text { regimen: } \\
\text { Time spent outdoors }\end{array}$ & $\begin{array}{l}\text { Diary completed each day of the trial } \\
\text { period } \\
\text { Journal completed prior to each of the } \\
3 \text { clinical follow up examinations }\end{array}$ & $\begin{array}{l}\text { Each morning the person recorded whether the cream was applied. } \\
\text { Derived variable: the percentage of days the cream was applied over the study period. } \\
\text { fournal: Participants recorded whether they were outside in either or both of the two hour } \\
\text { period(s) between } 11 \text { am and } 3 \text { pm over a seven day period } \\
\text { Derived variable: Percentage of occasions the participant was outdoors }\end{array}$ \\
\hline Covering up when outdoors & $\begin{array}{l}\text { Journal completed prior to each of the } \\
3 \text { clinical follow up examinations. (see } \\
\text { above) }\end{array}$ & $\begin{array}{l}\text { Fournal: As part of the seven day journal (see above) participants also indicated whether } \\
\text { they were wearing a hat, wearing a long-sleeved shirt, wearing another sunscreen or were in } \\
\text { the shade when outside. } \\
\text { Derived variable: The percentage of occasions that the participant was outdoors wearing a } \\
\text { hat and long sleeved shirt, wearing another sunscreen and/or in the shade. }\end{array}$ \\
\hline Use of other sunscreens & $\begin{array}{l}\text { From the questionnaires completed } \\
\text { before each of the } 3 \text { follow up clinical } \\
\text { examinations }\end{array}$ & $\begin{array}{l}\text { Question: "Since we gave you our cream about how many times have you used another } \\
\text { sunscreen on your arms? (hands/face)" } \\
\text { Possible responses (for each body part): Not at all, about once a month, a few times a month, } \\
\text { about once a week, a few times a week and every day. These response options were scored } \\
\text { from } 0-5 \text {. } \\
\text { Derived variable: Ratings were summed over the three body areas and an average score for } \\
\text { the three data points was calculated. }\end{array}$ \\
\hline $\begin{array}{l}\text { Use of other moisturising } \\
\text { creams }\end{array}$ & $\begin{array}{l}\text { From the questionnaires completed } \\
\text { before each of the } 3 \text { follow up clinical } \\
\text { examinations }\end{array}$ & $\begin{array}{l}\text { Respondents also indicated how often they had used another moisturiser on their hands, } \\
\text { arms or face. Scoring procedures were similar to those used for other sunscreen use. }\end{array}$ \\
\hline
\end{tabular}

\section{Results}

PARTICIPANTS AND WITHDRAWALS

Overall 2000 people (about $60 \%$ of the population over 40 in the town) attended for the skin examination. Five hundred and eighty eight participants with between one and 30 keratoses were enrolled at the beginning of the study, and 221 people in the base cream group and 210 in the sunscreen group completed the study. The remaining 157 people either withdrew or failed to attend the final appointment of the study. As table 2 shows, there was no significant difference in number of withdrawals between study groups, and no significant difference in baseline demographic or clinical features (including side effects of treatment) between those who completed and those that withdrew. Among the 488 people who completed the first clinical examination, and who answered the question on perceived treatment allocation, the proportion of people correctly guessing their treatment group

Table 2 Characteristics of people who withdrew and those who completed the study

\begin{tabular}{lccc}
\hline & $\begin{array}{l}\text { Withdrew } \\
(n=157)\end{array}$ & $\begin{array}{c}\text { Completed } \\
(n=431)\end{array}$ & $p$ \\
\hline $\begin{array}{l}\text { Sex: } \\
\quad \text { Male }\end{array}$ & $44 \%$ & $42 \%$ & 0.63 \\
Age (mean SD) & $63.2(13.0)$ & $62.6(10.5)$ & 0.63 \\
$\begin{array}{l}\text { Study group: } \\
\quad \text { Base cream }\end{array}$ & $47 \%$ & $51 \%$ & 0.31 \\
$\begin{array}{l}\text { Side effects: } \\
\quad \text { Present }\end{array}$ & $5 \%$ & $5 \%$ & 0.67 \\
$\begin{array}{l}\text { Skin type: } \\
\quad \text { Always burn } \\
\quad \text { Burn first, then tan }\end{array}$ & $24 \%$ & $21 \%$ & \\
$\quad \begin{array}{l}\text { Just tan } \\
\text { Solar keratoses: }\end{array} \quad$ Number at initial examination (mean SD) & $53 \%$ & $56 \%$ & \\
$\quad 23 \%$ & $23 \%$ & 0.72 \\
\hline
\end{tabular}

was similar for those who completed the study $(32.5 \%)$ and for those who later withdrew $\left(34.1 \%: \chi^{2}=0.07 ; \mathrm{df}=1 ; \mathrm{p}=0.79\right)$.

PERCEPTION OF TREATMENT ALLOCATION OVER THE LAST TWO MONTHS OF THE TRIAL

Of the 376 respondents who completed the study and who answered the question before the second and third examinations, perceived treatment (rated as definite or probable) corresponded with actual treatment in $111(29.5 \%)$ of respondents on both occasions; 96 (26\%) were incorrect on both occasions, and 169 (45\%) either indicated a "don't know" response on both occasions, or were incorrect on one occasion. Conditional on the 207 participants who were either correct or incorrect on both occasions, people were just as likely to be right as to be wrong when they stated their opinion about their treatment allocation $(z=1.04 ; p=0.15)$.

\section{DETERMINANTS OF CORRECT PERCEPTION OF} TREATMENT ALLOCATION

The proportion of correct responses did not differ between the two treatment groups, with $32.6 \%$ of the sunscreen groups and $26.5 \%$ of the base cream group giving correct responses $\left(\chi^{2}=1.72 ; \mathrm{df}=1 ; \mathrm{p}=0.19\right)$. As table 3 shows, skin type, the amount of time spent outdoors, the presence of side effects, perceptions of change in skin condition (and its interaction with treatment group) also did not significantly predict correct perception of treatment allocation. (Small numbers in some cells meant that the interaction between side effects and treatment group could not be examined in the 
Table 3 Logistic regression predicting correct identification of treatment allocation*

\begin{tabular}{|c|c|c|}
\hline Variable & No & OR $(95 \% C I)$ \\
\hline \multicolumn{3}{|l|}{ Treatment group: } \\
\hline Base cream $\dagger$ & 185 & 1.00 \\
\hline Sunscreen & 189 & $0.95(0.43,2.10)$ \\
\hline \multicolumn{3}{|l|}{ Skin type: } \\
\hline Always burn $\dagger$ & 81 & 1.00 \\
\hline Burn first, then tan & 213 & $0.91(0.52,1.61)$ \\
\hline Always tan & 80 & $0.91(0.45,1.83)$ \\
\hline \multicolumn{3}{|l|}{ Outside: } \\
\hline$<50 \%$ of the timet & 292 & 1.00 \\
\hline $\begin{array}{l}>50 \% \text { of the time } \\
\text { Perception of change in skin } \\
\text { condition } \neq\end{array}$ & 82 & $\begin{array}{l}0.96(0.55,1.67) \\
1.11(0.99,1.23)\end{array}$ \\
\hline $\begin{array}{l}\text { Perception } x \text { treatment } \\
\text { Side effects: }\end{array}$ & & $0.94(0.81,1.08)$ \\
\hline No† & 355 & 1.00 \\
\hline Yes & 19 & $0.61(0.20,1.90)$ \\
\hline
\end{tabular}

$\star$ Based on the 376 respondents who completed the study and who answered the question about perceived treatment allocation before the second and third examinations. Two cases had missing data on at least one other variable; 111 cases $(30 \%$ were classified as probably correct).

tReference group.

$\ddagger O R$ associated with increase of one point on the scale measuring perception of change.

logistic regression, but univariate analysis, stratifying by treatment group, showed there was no significant association between side effects and correct identification in either treatment group).

\section{EFFECTS OF CORRECT PERCEPTION OF}

TREATMENT ALLOCATION

Table 4 shows the mean scores (and 95\% confidence intervals) for the adherence measure and for each index of sun protection for those who guessed their treatment allocation and those that did not, separately for each treatment group. It is clear that adherence was high and use of other moisturisers and sunscreens was low for both treatment groups, regardless of whether or not participants guessed their correct treatment allocation. Participants in all conditions reported that they used additional sun protection on about one third of the occasions that they were outside between 11 am and $3 \mathrm{pm}$. The MANOVA indicated, using Wilks' criterion, that the combined indices measuring adherence to cream use and use of other sun protection during the study period were not significantly affected by actual treatment allocation $\left(F_{4,311}=1.47 ; \mathrm{p}=0.21\right)$, correct perception of treatment allocation $\left(F_{4}\right.$ $\left.{ }_{311}=0.90 ; \mathrm{p}=0.46\right)$ nor by their interaction $\left(F_{4}\right.$, $\left.{ }_{311}=1.63 ; \mathrm{p}=0.17\right)$.
EFFECT OF INDICES OF SUN PROTECTION AND ADHERENCE ON REMISSIONS OF SOLAR KERATOSES Adherence was divided into tertiles, representing categories of $100 \%$; $95-99 \%$; and less than $95 \%$ use of creams. As table 5 shows, Poisson regression analysis showed a significantly lower difference ratio for solar keratoses in the sunscreen group compared with the base cream group $(R R=0.55 ; C I=0.46,0.64)$, and for women compared with men $(R R=0.76$; $\mathrm{CI}=0.63,0.93$ ) but no independent effect of any of the indices of other sun protection or adherence.

\section{Discussion}

This trial required a considerable commitment from participants, in that they were asked to apply a cream every morning over a long period of time (seven months). Given the nature of the treatments, one being a high SPF sunscreen, highly effective for preventing sunburn, it seemed feasible that participants could guess which treatment they were receiving. Leventhal has suggested that under these types of conditions, particularly potential loss of blinding, participants will adopt other behaviours at variance with study protocols, and that these behaviours may effect clinical outcomes. ${ }^{1}$

Only around $30 \%$ of participants correctly guessed their treatment allocation, with the remainder either guessing incorrectly or being unable or not prepared to offer an option. It seems that blinding was effective in this study. This result is very surprising when the intervention is considered-using or not using a high SPF sunscreen over an Australian summer. Correct perception was not related to skin type, differences in side effects between the two treatments, or to a differential perception of skin changes that might be attributed to treatment. Surprisingly, the correct perception was also not related to the amount of time participants spent outdoors. It is possible that participants were using other cues that were not measured to reach a correct decision about which cream they were receiving. However, that $70 \%$ of the sample did not guess their correct treatment group, suggests that this identification either may not have been a priority for participants or that the task may not have been as easy as it may have seemed.

We thought that if participants were aware of their treatment allocation this would affect their behaviour. For example, if a person believed that they were applying sunscreen they would feel protected against developing solar

Table 4 Mean scores (95\% CI) of indices of adherence and other sun protection behaviours *

\begin{tabular}{|c|c|c|c|c|c|}
\hline \multirow[b]{2}{*}{ Index } & \multirow[b]{2}{*}{$\begin{array}{l}\text { Possible } \\
\text { range }\end{array}$} & \multicolumn{2}{|l|}{ Base Cream } & \multicolumn{2}{|l|}{ Sunscreen } \\
\hline & & $\begin{array}{l}\text { Correct perception } \\
(n=61)\end{array}$ & $\begin{array}{l}\text { Incorrect perception } \\
(n=126)\end{array}$ & $\begin{array}{l}\text { Correct perception } \\
(n=50)\end{array}$ & $\begin{array}{l}\text { Incorrect perception } \\
(n=139)\end{array}$ \\
\hline $\begin{array}{l}\text { Adherence } \\
\text { Covering up when }\end{array}$ & $0-100 \%$ & $94.9(93.1,96.8)$ & $94.4(92.4,96.5)$ & $94.6(90.5,98.7)$ & $95.6(93.8,97.4)$ \\
\hline outdoors & $0-100 \%$ & $32.0(23.5,40.6)$ & $33.3(27.5,39.1)$ & $33.2(25.0,41.1)$ & $29.6(24.4,34.8)$ \\
\hline Use of other sunscreens & $0-15$ & $1.7(0.9,2.5)$ & $2.4(1.8,3.1)$ & $1.7(0.8,2.7)$ & $1.3(0.8,1.8)$ \\
\hline Use of other moisturisers & $0-15$ & $3.1(2.1,4.2)$ & $3.4(2.1,4.7)$ & $3.1(2.4,3.9)$ & $2.3(1.6,2.9)$ \\
\hline
\end{tabular}

*Based on the 376 respondents who completed the study and who answered the question about perceived treatment allocation before the second and third examinations. 
Table 5 Poisson regression predicting outcome (ratio of total number of solar keratoses at the beginning and the end of the study)

\begin{tabular}{lll}
\hline Variable & $N o^{*}$ & $R R(95 \% \mathrm{CI})$ \\
\hline Treatment group: & & \\
$\quad$ Base cream $\dagger$ & 213 & 1.00 \\
$\quad$ Sunscreen & 204 & $0.55(0.46,0.65)$ \\
Sex: & 171 & 1.00 \\
$\quad$ Male $\dagger$ & 246 & $0.76(0.63,0.93)$ \\
$\quad$ Female & & $0.86(0.29,2.54)$ \\
Use of other moisturisers $\ddagger$ & & $1.82(0.63,5.25)$ \\
Use of other sunscreens $\ddagger$ & & $1.00(0.99,1.00)$ \\
Covering up when outdoors $\ddagger$ & & \\
Adherence: & 120 & 1.00 \\
$\quad<95 \% \dagger$ & 130 & $0.94(0.77,1.15)$ \\
$95-99 \%$ & 167 & $0.83(0.67,1.02)$ \\
$100 \%$ &
\end{tabular}

^Fourteen cases had missing data on at least one variable. tReference group.

$\ddagger R R$ associated with increase of one point on scales used.

keratoses and perhaps have a stronger commitment to the study's goals, manifest as being less likely to drop out and more likely to adhere with treatment than other participants. On the other hand, if a person believed that they were in the base cream group they might compensate for this by using other forms of sun protection, particularly other sunscreens during the study period. There were no significant differences in withdrawals, adherence or other sun protection between different treatment groups nor between those who correctly guessed their treatment allocation and those that did not. The lack of a significant interaction shows that people who correctly guessed that they were in the base cream group were no more likely to use additional sun protection than other participants and that people who believed they were applying sunscreen were no more likely to comply with treatment than others. Overall, adherence with treatment was high and the use of other sun protection behaviours was low for people in all groups. It seems that people in this trial, having made a commitment to the study protocol adhered to it throughout the trial and it made no difference whether they had decided which treatment they were receiving.

During the planning stages of this trial, it was recognised that other behaviours of participants might be a threat to the internal validity of the trial. Therefore a number of strategies were used to improve recruitment into the trial and to increase the likelihood that participants would adhere to study protocols. These strategies incorporated the behavioural principles of engendering community cooperation, using appropriate credible models, providing rewards for participation, using a number of different sources to give clear instructions and rationale, and incorporating regular reinforcing messages throughout the study. ${ }^{4}$

Promotion of the study and the organisation of the clinical examinations were conducted in close collaboration with local personnel and organisations, to enhance a spirit of cooperation between the study team and the community. The senior investigator of this trial (RM) was well known in the community through previous skin cancer incidence studies that had been conducted in this district, and which had resulted in favourable publicity for the region. ${ }^{6} 7$

\section{KEY POINTS}

- The behaviour of participants that do not accord with study protocols may threaten the validity of outcomes in clinical trials.

- Strategies that incorporated behavioural principles such as credible models, engendering community cooperation, and regular, clear reinforcing messages were used to increase the likelihood that people would adhere to study protocols.

- A sufficient level of commitment to study procedures was achieved so that participants in this trial of sunscreen cream did not adopt other behaviours that affected outcomes.

- Behavioural strategies that encourage cooperation should be incorporated and deviations from protocols investigated in all clinical trials.

The senior investigator therefore maintained a high profile while promoting the study in the community and conducting the trial.

The study also ensured that the community was given something for their cooperation in the study. The initial examination offered a free skin check and pertinent advice for all members of the community over the age of 40 . Given the high risk of skin cancer among Australians in this age group, ${ }^{8}$ this was thought to be an appropriate and effective strategy for both recruiting people into the study and for giving something to the community. About $60 \%$ of the population over 40 in the town took up the offer of the clinical examination, attesting to the suitability of the strategy. It was recognised that the way the alternative treatments were described to potential participants could affect adherence to study protocols so both creams were presented as alternative treatments. The rationale for blinding was also explained to participants both verbally and in written material. Participants were also given clear statements of what was expected in terms of recommending the use of other sun protection during the study period. These messages were reinforced at the each subsequent clinical examination. So although participants were expected to maintain an unusual behaviour over quite a long period, there was regular reinforcement for doing so.

It seems that the incorporated strategies were successful, and that a sufficient level of commitment to study procedures was achieved among trial participants, so that the potential threat to the internal validity was not realised. The results of the trial, in terms of the effects of treatment on clinical outcome, therefore can be taken to be internally valid. However there is a need for caution in generalising from these findings to other trial settings in which the study population may not be as committed or well informed about adherence to the protocol.

We recommend that the potential threat to validity posed by the behaviour of participants in clinical trials be recognised at an early stage in the development of trials, and that strategies 
to deal with these be an integral part of study protocols.

We would like to thank Drs P Foley, C Hadwen, D McColl, F Bruce, F Watkins, S Gilmore, J Horton who examined patients members of Rotary, Mr R Were, the City of Maryborough, and the Maryborough Community Health Centre for assistance and use of facilities; Jenny Greed, for her dedicated effor throughout the study; Craig Wilson and other volunteers for help in questionnaire administration; and Barbara McKenzie and Ngaire Donoghue for computing assistance.

Funding: the study was supported by grants from the Victorian Health Promotion Foundation, Melbourne; Skin and Cancer Foundation, Sydney; Skin and Psoriasis Foundation, Melbourne; the Lloyd Williams Trust, Maryborough; The Sydney Melanoma Foundation; and The Australasian College of Dermatologists. Jill Cockburn and Damien Jolley were supported by Victorian Health Promotion Foundation Public Health Fellowships.

Conflicts of interest: none.
1 Leventhal H, Nerenz D, Leventhal E, Love R, Bendena L. Behavioural dynamics of clinical trials. Prev Med 1991;20:132-46.

2 Pocock SJ. Clinical trials. Chichester: John Wiley, 1983.

3 Thompson SC, Jolley D, Marks R. Reduction of solar keratoses by regular sunscreen use. $N$ Engl f Med 1993;329: $1147-51$.

4 Kanfer FH \& Goldstein AP, eds. Helping people change. A text book of methods. New York: Permagen Press, 1986.

5 Green LW, Kreuter MW. Health promotional planning: an educational and environmental approach. Mountain View CA: Mayfield Publishing, 1994.

6 Marks R, Rennie G, Selwood TS. Malignant transformation of solar keratoses to squamous cell carcinoma in the skin: a prospective study. Lancet 1988;i:795-7.

7 Marks R, Jolley D, Dorevitch AP, Selwood TS. The incidence of non-melanocytic skin cancer in an Australian population: results of a five year prospective study. Med $\mathcal{f}$ Aust 1989;150:475-8.

8 Marks R, Staples M, Giles GG. Trends in non-melanocytic skin cancer treated in Australia: the second national survey. Int f Cancer 1993;53:585-90. 